\title{
Behavior and Attitude of Students in the New Normal Perspective of Learning
}

Leovigildo Lito D. Mallillin ${ }^{1 *}$, Imelda C. Lipayon, LPT ${ }^{2}$, Jocelyn B. Mallillin, LPT ${ }^{3}$, Dayanara May S. Mallillin, LPT ${ }^{4}$

${ }^{1}$ Ph.D., Consultant and Research Specialist

${ }^{2}$ Novaliches High School, High school in Quezon City, Philippines

${ }^{3}$ San Bartolome High School, High school in Quezon City, Philippines

${ }^{4}$ Bungad Elementary School in Isabela, Philippines

\begin{abstract}
Article History
Received: 24.02 .2021

Accepted: 08.03.2021

Published: 13.03.2021
\end{abstract}

Journal homepage: https://www.easpublisher.com

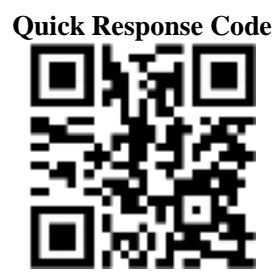

Abstract: Behavior and attitude of students in the new normal perspectives have an impact in their learning process. It contributes to self-determination in the new normal classes and framework theory of learning engagement and supports the influence of the new normal classes and learning perspective development. The study examines how the observed behavior and attitude of students in the new normal perspective of learning and identify how the behavior and attitude of students can be addressed in the new normal perspective of learning among the respondents. The study employs the qualitative descriptive phenomenology research design and method. It is a scientific and philosophy method that undertakes the variation of the study. It is a typical method of data collection involved in the Focus Group Discussion (FGD), observation, document review of specific events. The study comprised 14 parents as respondents. Results show that behavior and attitude of students during their online learning classes are lazy to study, wake-up late in the scheduled time of their classes, students are enjoying their sleep in the morning, lack of sleep, and are hungry because they have not eaten their breakfast during their online classes. Moreover, adjustment in online classes show that it is very early, students are not used for online classes, students are not serious in their studies, and students have difficulties in their online classes, while internet issues show that students encounter slow connection, busy doing online game aside from their online classes, and insufficient load for internet connection.

Keywords: behavior and attitude of students, new normal learning perspective, online classes, online learning, online classes adjustment, internet issues in online classes, and new normal classes.

Copyright (C) 2021 The Author(s): This is an open-access article distributed under the terms of the Creative Commons Attribution 4.0 International License (CC BY-NC 4.0) which permits unrestricted use, distribution, and reproduction in any medium for non-commercial use provided the original author and source are credited.

\section{INTRODUCTION}

Behavior and attitude of students in the new normal perspectives have an impact in their learning process. The adjustment portrays the behavior and attitude in their learning process from the traditional learning and in the new normal process. The behavior and attitude of students address the future and possible direction, several outcomes, and implication of the new normal classes and in the learning process for advance technology in increasing the interaction and communication process of learning. It develops the support of the new normal classes and learning perspective of students where it is vital to gain knowledge on their enhancement, Purwanto, Ichsan, Gomes, Rahman, \& Irwandani [1]. The effectiveness and efficiency of the technology vary based on the behavior and attitude of students in the quality output of learning. Students cannot escape to compare the traditional face to face learning from the new normal classes. The traditional face to face learning is content perceived relevance modality where it utilizes the advance technology process understandable in instructional modern technology rather than the new normal learning process where the evolution is inextricably taught in the human process of technology learning, Dziuban, Graham, Moskal, Norberg, \& Sicilia [2].

On the other hand, due to the situation of the new normal classes, students must be motivated particularly on the attitude and behavior of the improved learning process especially on their study habits. Student study habits are still other pressing issues in the new normal classes since students are not monitored personally. Student study habits can only be monitored through virtual processes. There are many factors of motivation given to students to enhance their learning process. Different learning process and style 
can improve the development of students and their initiative in the new normal classes. It provides the learning style that can focus on the motivation to study to enhance their learning that intervenes and provides action on the study habit improvement through proper motivation, Mallillin, Mallillin, \& Laurel [3]. It fits and models the students in their comfort to the best learning study. It provides students in the learning process to the new normal classes and its effectiveness especially students are given proper motivation to study. The new normal classes provide a better impact on student motivation to study as an alternative to the traditional learning process, Aznam et al., [4].

Moreover, the new normal perspective learning of students in the various domains of learning must be given emphasis to help in the behavior and attitude in the learning process. It reinforces the learners on their leverage and realistic learning. It provides curriculum learning framework and direction, Narvekar et al., [5]. Different domains of learning must be designed and must be provided on different activities to explore the in-depth activities of learning. It provides and helps in various ways and styles based on the learners' needs. The different domains on the area of the affective learning, psychomotor learning, and cognitive learning provide in the framework and pedagogy on the learners academic performance in terms of skills, behavior, and attitude in the school academic performance. It shows students to execute the ability and to carry the lesson implemented in cognitive learning. Students have proper attention and motivation to learn and to satisfy, willing to participate in the learners worth behavior and attitude, acceptance, belief, commitment to values, and preference in the affective learning. The learners can relate to the auditory, visual, body movement, coordination or touch in the information and ability from the atmosphere in the psychomotor learning. It also provides the domain of learning in the performance of students in their academe that acquires knowledge and skills in the different situations of skills and learning. It provides different activities in the classroom of learning that focuses on the lesson and provides output of students in their new normal perspective of learning, Mallillin [6].

Consequently, the behavior and attitude of students in their new normal perspective of learning provides an approach that combines the afforded and benefits of their online component of learning. This can be done through blended learning, face to face on new normal learning processes. It highlights the blended learning and challenges in the mode of instruction on the understanding of the existence on the process of learning and challenges in the new normal blended component. It provides challenges and identifies the systematic online blended learning component in the new normal perspective. The challenges in the learning technology and self-regulation are on the part of the learners. The provision and challenges in the instructional suitable technology, support and effective training among teachers are the educational institutions, Kamsin, \& Abdullah [7]. Different sectors including the different educational institutions have devastated the various impacts on the current covid pandemic. It is the approach in the new normal student learning, Mallillin, Carag, Mallillin, \& Laurel [8]. There is a new light in the emerging challenges and opportunities to consider in the behavior and attitude of students in the new normal and perspective of learning. It attempts to rethink the new normal process in education on their curriculum. It provides implications on the crises of the goal, content, evaluation, and approach of curriculum in the new normal and learning perspective of students, Cahapay [9].

\section{Research Question}

1. How the behavior and attitude of students in the new normal perspective of learning are observed.

2. How the behavior and attitude of students can be addressed in the new normal perspective of learning among the respondents.

\section{Theoretical Lens}

The study is anchored on Self-Determination Theory (STD), Ryan, \& Deci [10], as this theory deals on the intrinsic and extrinsic motivation from a selfdetermination theory perspective by definition, practices, and future direction among the learners. It provides the factors and understanding on the broad framework to undermine and facilitate the autonomous, intrinsic, and extrinsic motivation and on psychological and wellness particularly on the direct relevance and issues to educational settings. The theory provides selfdetermination on both the well-internalized and intrinsic motivation from the extrinsic motivation array that predict positive outcomes across levels of education and cultural context that can support and enhance the psychological need of students for competence, autonomy and relatedness. It helps both the teacher and students to motivate themselves in the new normal perspective of learning that can constrain the impact of the institutional pressure, control mandate, and leadership style. Despite of the substantial importance and evidence of the learning context and satisfaction of the psychological needs of students, the curriculum is anchored on the policies of the educational institutions and fails to support the teachers' needs and students' needs.

\section{Research Design}

The study employs the qualitative descriptive phenomenology research design and method which is widely used to describe and to explore the study under investigation particularly in the experiences of the individual respondents. It is a scientific and philosophy method that undertakes the variation of the study. It is a typical method of data collection involves in the focus group discussion, observation, document review of 
specific events. A qualitative descriptive method and design utilizes the uncomplicated description that focuses on the desired detail of why, where, what, and when of an experience or events.

On the other hand, it discusses how to undertake and understand the thematic analysis based on the descriptive phenomenology. The principles and methods to guide the process of the analysis offered on the phenomenological philosophy ground in relation to the validity and scientific rigor that can be achieved. It provides the thematic analysis based on the phenomenology and descriptive tradition usefulness of the description analysis that undertakes the process and outline. It explains the methods and principles, processes, and analyses in the organized experience and meaningful data, Sundler, Lindberg, Nilsson, \& Palmér [11].

\section{Research Participants}

The participants of the study are the parents of students in the various selected educational institutions. They are credible to be the participants because they observed the actual situation of the behavior and attitude of their children in the new normal perspective of learning. They know the circumstances on the behavior and attitude of their children in the process of their learning. The study comprised 14 parents as respondents.

\section{Research Instruments}

To obtain the important information of the study, the interview guide is formulated for the respondents and is based on the research question in the research problem. There is a probe question given to the respondents. Question given to the respondents examines the observation of the behavior and attitude of children in the new normal and learning perspective, knowledge, and experience to gather important views that can be shared for better improvement. It assures that questions given will not take much time for the respondents. This is given emphasis so that smooth flow of work of the participants will not be affected considering the itinerary of parents at home. This is in compliance with the research ethics and standard.

\section{Procedure in Gathering Information}

The information of the study is primarily acquired through Focus Group Discussion (FGD) from the various educational institution lecturers and teachers. To further elaborate the process, the following steps are observed.

It is observed that most of the lecturers have problems with the attitude and behavior of students in the new normal classes and learning perspective where they can give solutions on the possible issues challenging tasks. It illustrates the consensus of the practitioners and researchers in the rapport and
}

development of disclosure and facilitates cooperation in the context of the gathered information, Gabbert et al., [12].

\section{Formulation of Paper}

After the mapping, the construction of a research paper is established looking for positive output of the issues identified regarding the behavior and attitude of students in the new normal classes and learning perspective, Ratan, Anand, \& Ratan [13].

\section{Validation}

After the method is determined, the research questions are formulated and validated by expert qualitative researchers. The suggestions and recommendations are given emphasis prior to the finalization of the questionnaire, Taylor et al., [14].

\section{Conduct of FGD}

Before the conduct of the interview, parents are given prior instruction and announcement that researchers wanted to conduct an interview on the behavior and attitude they observed among their children during the new normal phase of learning. Parents are very cooperative because they want to contribute to the success of the study.

\section{Analysis of Questionnaire}

After the FGD is conducted, the researchers gathered all the necessary answers for thematic analysis of data for interpretation, Zens, Brammertz, Herpich, Südkamp, \& Hinterseer [15].

\section{Trustworthiness of the Study}

Trustworthiness and credibility are the problems and issues in the qualitative research that need to be addressed. It provides the trustworthiness and concept through different criteria as to confirmability, dependability, transferability, and credibility. It provides the authenticity to depict the researchers ability in a diverse accurate reality in the collected data of the participants, Kyngäs, Kääriäinen, \& Elo [16], as follows:

\section{Confirmability}

It provides the degree of neutrality and describes the extent of the findings and reflection of the respondents, experiences, opinions rather than of interest, motivation, and biases. It is concerned with the establishment of the interpretation that will derive from the data to demonstrate how the conclusion is required.

\section{Dependability}

It ensures the achieved dependability of the study into traceability, logical process and clearly documented. It demonstrates the process of dependability of the process in the study.

\section{Transferability}


Focuses on the application of the findings where it provides the inquiry and generalization of the qualitative research. It provides the responsible description of the findings in transferability.

\section{Credibility}

It is defined as the truth and confidence of the findings. It claims to be credible in determining the reliability of the study. It addresses to fit the views of the research representation as technique to address the engagement of the data collection, persistent observation, and research triangulation. It provides to increase the research process and interpretation. It utilizes the credibility of the research and intervention to help in the effective research organization through generation of knowledge and application of research, Shufutinsky [17].

\section{RESULT}

Table-1: Themes and Core Ideas on the Behavior and Attitude of Students in their Online Classes

\begin{tabular}{|c|c|c|}
\hline Theme & Frequency of Response & Core Idea \\
\hline a. Behavior of students during online classes & $\begin{array}{l}\text { variant } \\
\text { general } \\
\text { general } \\
\text { variant }\end{array}$ & $\begin{array}{ll}> & \text { Lazy } \\
> & \text { woke up late } \\
> & \text { still enjoying sleep } \\
> & \text { lack of sleep } \\
> & \text { hungry }\end{array}$ \\
\hline b. Online Classes Adjustment & $\begin{array}{l}\text { general } \\
\text { general } \\
\text { general } \\
\text { general }\end{array}$ & $\begin{array}{ll}> & \text { online class is so early } \\
> & \text { not used for online classes } \\
> & \text { not serious in studies } \\
& \text { have difficulties in online classes }\end{array}$ \\
\hline c. Internet Issue & $\begin{array}{l}\text { general } \\
\text { general } \\
\text { general }\end{array}$ & $\begin{array}{l}>\text { slow internet connection } \\
>\quad \text { expose to online game } \\
>\text { no load for internet connection }\end{array}$ \\
\hline
\end{tabular}

\section{A. Behavior and attitude of students during online classes}

The behavior and attitude of students in the online classes determine the effects of nature based education curriculum and implementation in the new normal learning perspective since education is a continuous learning process. It provides framework and analysis on the improved learning process in new normal schemes. It establishes and develops proper technique of teaching so that behavior and attitude of students will boost their morale in the perspective of learning by means of the delivery mode based on the need of the learners, Mallillin, Mallillin, Carag, Collado, \& Largo [18]. They say:

"Their children are too lazy to study". (P6, P13, T1)

"They woke up late on their scheduled time of classes". (P11, T1)

"Their children are enjoying their sleep in the morning”. (P7, T1)

"Most of their children have a lack of sleep that affects their classes". (P1, P4, T1)

"Their child is hungry because breakfast is not yet served". (P3, T1)

\section{B. Online classes adjustment}

Generally, the online classes adjustment describes the various virtual activities in the assessment of the behavior and attitude of students in their online lesson toward their academic performance.
It constraints and identifies the new normal learning process and adjustment. Lecturers also identify the challenges from adjusting traditional classes to new normal classes where both teachers and students have difficulties in coping with the learning perspective of students Putri et al., [19]. However, the following are observed:

"Online class is very early among students". (P2, T2)

"Students are not used for online classes". (P9, T2)

"Students are not serious in their studies". (P12, T2)

"Students have difficulties in online classes. (P10, T2)

\section{Internet issue}

The Internet is very useful to connect students in their online classes and is becoming increasingly important for the students' lives to boost the morale of the learning process enhancement. Simultaneously, the range of online activities is also broadening. However, the technology adoption mainly focuses on internet use in general and pays attention to various activities in online classes. The Internet is vital in performing all online activities. Hence, the following are observed:

"There is slow internet connection during online classes". (P5, T3-1)

"Most students are doing online games aside from the online classes. (P8, T3-1) 
"No enough load for internet connection". (P14, T3-)

\section{DISCUSSION}

Behavior and attitude of students in the new normal is uncontrollable especially adjustment of classes is abrupt from traditional classroom setting to online setting. There are many adjustments to be considered in the teaching process and learning perspective. The new normal situation in the student learning perspective influences the way it uses to study, to live, and to work. It is an abrupt transition from traditional learning face to face to online learning process paradigm shifting viewed in the various educational institutions. It examines the impact of selfdetermination in the new normal classes and framework theory of learning engagement. It provides support on the influences of the new normal classes and learning perspective of students. It contributes to the behavior and attitude of students in developing their online learning to new normal learning perspectives, Shah, Shah, Memon, Kemal, \& Soomro [20]. On the other hand, the new normal classes are forced to virtual transition or blended learning depending on the area where various teaching techniques are introduced due to the current pandemic. It actively provides a way to explore the online learning process in utilizing various features and technologies in teaching. It also provides guidance to empower the transition of learning synchronous lessons in a virtual learning process for effective distance learning, Sharp, Norman, Spagnoletti, \& Miller [21].

On the other hand, the behavior and attitude of students in their online classes show that most of them are lazy to study. This means there is an effect on their study habits and learning styles. This is one of the pressing problems and issues of students despite the motivation being given by both parents and teachers to help them improve their learning perspective. Doing so would enhance the student learning process. To address the issue, motivation must not be stopped due to the behavior and attitude of students in their learning process. Learning process must be given emphasis on motivation where it helps students to improve their learning perspective in the new normal classes Mallillin, Mallillin, \& Laurel [3]. It also shows that students have difficulties to adjust themselves in waking-up during their scheduled time of classes. This is the effect of the pandemic where most of their time is spent in their sleep or vice versa where they sleep late due to some activities like playing games, using their mobile phone, internet, facebook, chatting etc. Due to this situation, the time and schedule of classes are being affected, Sintema [22]. It also shows that students are enjoying their sleep in the morning. At this stage, students are fond of sleeping. Time management must be observed by students which is a vital component in their success. It intervenes and indicates the positive effect on the behavior and attitude of students in their new normal learning perspective, Baker, Evans, Li, \&
Cung [23]. Furthermore, students also observed that most of them are hungry during their online classes because breakfast is not yet served which means students are physically present but mentally absent because of an empty stomach. There is no learning process when students have an empty stomach, Ilieva, Ahmed, \& Yan [24].

Moreover, the online classes adjustment of students shows that they have complained about their online classes because it is very early which affects their learning perspective in the new normal. They have difficulty in the adjustment of their time schedule. They are not used to it due to the current pandemic. This has an effect on the transition and capacity of their learning process in online new normal classes, distance learning, and blended learning. It indicates that support must be given to them especially on the part of the parents and family members in order that learning perspective in the new normal will not be affected. It confirms the process of transition on the new normal classes to gain success in the learning enhancement of students, Basilaia, \& Kvavadze [25]. It also shows that students are not used in the online classes. They said they have difficulty in the adjustment of their online classes. It is an approach to examine and use for both teachers and students in their dependency to school adjustment in the new normal that engages in externalizing behavior, achievement, prosocial behavior, and internalizing behavior, Roorda, Zee, \& Koomen [26]. Moreover, it also reveals that students are not serious in their studies. Their studies seem to be taken for granted, easy go lucky, boring routine kind of learning because the lesson is done virtually, pass and submit the task just to finish the lesson for the day. Intellectual ability is not sufficient when studies are taken for granted. It indicates that studies take effort in learning and in the context condition of the process especially during pandemic. It examines how studies are taken for granted because they are not serious about it. Selfpractice and self-evident hinder the progress of students, Skakni [27]. Though students have difficulties in their online classes, motivation must be given emphasis to develop interest in the learning process. They need to adapt the curriculum provided by the various educational institutions to continue achieving the goals through continuous education. Educational institutions follow a set of lectures based on the new normal trends. Adjustment is not easy to do but when desire is present, everything will be possible in learning to include the necessity of online learning as to strength, weakness, opportunity, and challenges in the mode of learning during times of crises, Jeong, \& So [28].

Furthermore, the internet issues among the participants show slow connection during online classes. This is true because of the bulk of internet users and especially to a place where dead signals of the internet are observed. Slow connection of the internet is a barrier to the learning process of students in various 
educational institutions especially that online classes are set-up with advanced technology of learning like google meet, zoom, messenger etc. It depicts how importance the internet connection would be during the online classes. Students have difficulties in coping their learning process and innovation on the barrier of the learning enhancement including communication with teachers in understanding the best style of learning among them, Octaberlina, \& Muslimin [29]. In addition to the internet connection, students are also doing online games aside from their online classes. This means that students are doing two things, playing and studying at the same time like heating two birds in one stone. Gadgets or computers used in online classes must be restricted to games to avoid disturbance during their online classes. This can contribute to the stress condition for both teachers and students. It even distracts the coping mechanism of students in their learning process. It validates the psychological distraction and concept of students in their behavior and attitude in the new normal classes as far as technology is concerned, Tarafdar, Maier, Laumer, \& Weitzel [30]. Lastly, students also experienced no internet connection because of insufficient load where it affects their online classes. Most of them have no load because of financial constraints due to their status in life where they belong to below poverty line level. They need to suffice their stomach rather than buying loads for internet connection in which their online classes are affected. It is a vital step in the learning process and issues that need to be addressed among the family members of students. When the issue will not be addressed definitely, it will be a disaster among the learners, Xia, Wang, Song, Chen, \& Li [31].

\section{CONCLUSION}

Based on the result of the finding of the study, the following conclusions are observed:

1. Behavior and attitude of students during their online learning classes show students are lazy to study, they even wake-up late in the scheduled time of their classes because students are enjoying their sleep in the morning, most of their children have lack of sleep that affect their classes, and their children are hungry because they have not eaten their breakfast during their online classes.

2. Online class adjustment shows that classes are very early, students are not used for online classes, students are not serious in their studies, and students have difficulties in their online classes.

3. Internet issues show that students encounter slow connection during online classes, most students are busy doing online game aside from their online classes, and insufficient load for internet connection.

\section{RECOMMENDATION}

Based on the findings and conclusions, the following recommendations are offered:
1. Students must be motivated properly in their online classes because most of them are lazy. Motivation can de done by both parents and teachers. There is a need to motivate students properly in their new normal classes to enhance their learning perspective. Behavior and attitude of students must be addressed properly because most of them are not aware of their online classes by waking up late during their classes because they enjoy their sleep in the morning.

2. Schools must schedule online classes based on the needs of students because they are not used in online classes. They have difficulty in adjusting themselves from traditional classes to online classes giving emphasis on the importance of online classes to achieve a better learning perspective in the new normal classes among students.

3. Schools, teachers, and parents can allocate budget for internet load because most students cannot attend their online classes due to insufficient load for internet connection. Load provided must be allocated on online classes only because some students used their internet connection for online games.

\section{REFERENCES}

1. Purwanto, A. G. U. N. G., Ichsan, I. Z., Gomes, P. W. P., Rahman, M. M., \& Irwandani, I. (2020). ESBOR during COVID-19: Analysis students attitude for develop 21st century environmental learning. Journal of Sustainability Science and Management, 15(7), 20-29.

2. Dziuban, C., Graham, C. R., Moskal, P. D., Norberg, A., \& Sicilia, N. (2018). Blended learning: the new normal and emerging technologies. International journal of educational technology in Higher education, 15(1), 1-16.

3. Mallillin, L. L., Mallillin, J. B., \& Laurel, R. D. (2020). Learning Styles: A Motivation to Study Habits of Students.

4. Aznam, N., Jumadi, J., Nurcahyo, H., Wiyatmo, Y., \& Perdana, R. (2021). Motivation and Satisfaction Level of Graduate Student: The Blended Learning with Peer Tutor (BL-PT) Model in New Normal Era. Journal of Educational Science and Technology (EST), 7(1).

5. Narvekar, S., Peng, B., Leonetti, M., Sinapov, J., Taylor, M. E., \& Stone, P. (2020). Curriculum learning for reinforcement learning domains: A framework and survey. Journal of Machine Learning Research, 21(181), 1-50.

6. Mallillin, L. L. D. (2020). Different Domains in Learning and the Academic Performance of the Students. Journal of Educational System, 4(1), 1-11.

7. Rasheed, R. A., Kamsin, A., \& Abdullah, N. A. (2020). Challenges in the online component of blended learning: A systematic review. Computers \& Education, 144, 103701. 
8. Mallillin, L. L. D., Carag, E. A., Mallillin, J. B., \& Laurel, R. D. (2020). Integration of knowledge through online classes in the learning enhancement of students. European Journal of Open Education and E-learning Studies, 5(1).

9. Cahapay, M. B. (2020). Rethinking education in the new normal post-COVID-19 era: A curriculum studies perspective. Aquademia, 4(2), ep20018.

10. Ryan, R. M., \& Deci, E. L. (2020). Intrinsic and extrinsic motivation from a self-determination theory perspective: Definitions, theory, practices, and future directions. Contemporary Educational Psychology, $61,101860$.

11. Sundler, A. J., Lindberg, E., Nilsson, C., \& Palmér, L. (2019). Qualitative thematic analysis based on descriptive phenomenology. Nursing Open, 6(3), 733-739.

12. Gabbert, F., Hope, L., Luther, K., Wright, G., Ng, M., \& Oxburgh, G. (2020). Exploring the use of rapport in professional information-gathering contexts by systematically mapping the evidence base. Applied Cognitive Psychology.

13. Ratan, S. K., Anand, T., \& Ratan, J. (2019). Formulation of research question-Stepwise approach. Journal of Indian Association of Pediatric Surgeons, 24(1), 15.

14. Taylor, S., Landry, C. A., Paluszek, M. M., Fergus, T. A., McKay, D., \& Asmundson, G. J. (2020). Development and initial validation of the COVID Stress Scales. Journal of Anxiety Disorders, 72, 102232.

15. Zens, M., Brammertz, A., Herpich, J., Südkamp, N., \& Hinterseer, M. (2020). App-based tracking of selfreported COVID-19 symptoms: analysis of questionnaire data. Journal of medical Internet research, 22(9), e21956.

16. Kyngäs, H., Kääriäinen, M., \& Elo, S. (2020). The trustworthiness of content analysis. In The application of content analysis in nursing science research (pp. 41-48). Springer, Cham.

17. Shufutinsky, A. (2020). Employing use of self for transparency, rigor, trustworthiness, and credibility in qualitative organizational research methods. OD Practitioner, 52(1), 50-58.

18. Mallillin, L. L. D., Mallillin, J. B., Carag, E. A., Collado, J. B., \& Largo, M. G. D. (2020). A Framework in Online Learning Process: A Guide to Educational Teaching During Covid 19 Pandemic. European Journal of Open Education and E-learning Studies, 5(2).

19. Putri, R. S., Purwanto, A., Pramono, R., Asbari, M., Wijayanti, L. M., \& Hyun, C. C. (2020). Impact of the COVID-19 pandemic on online home learning: An explorative study of primary schools in Indonesia. International Journal of Advanced Science and Technology, 29(5), 4809-4818.

20. Shah, S. S., Shah, A. A., Memon, F., Kemal, A. A., \& Soomro, A. (2021). Online learning during the
COVID-19 pandemic: Applying the selfdetermination theory in the 'new normal'. Revista de Psicodidáctica (English ed.).

21. Sharp, E. A., Norman, M. K., Spagnoletti, C. L., \& Miller, B. G. (2021). Optimizing Synchronous Online Teaching Sessions: A Guide to the "New Normal" in Medical Education. Academic pediatrics, 21(1), 1115.

22. Sintema, E. J. (2020). Effect of COVID-19 on the performance of grade 12 students: Implications for STEM education. Eurasia Journal of Mathematics, Science and Technology Education, 16(7), em1851.

23. Baker, R., Evans, B., Li, Q., \& Cung, B. (2019). Does inducing students to schedule lecture watching in online classes improve their academic performance? An experimental analysis of a time management intervention. Research in Higher Education, 60(4), 521-552.

24. Ilieva, R. T., Ahmed, T., \& Yan, A. (2019). Hungry minds: Investigating the food insecurity of minority community college students. Journal of Public Affairs, 19(3), e1891.

25. Basilaia, G., \& Kvavadze, D. (2020). Transition to online education in schools during a SARS-CoV-2 coronavirus (COVID-19) pandemic in Georgia. Pedagogical Research, 5(4).

26. Roorda, D. L., Zee, M., \& Koomen, H. M. (2020). Don't forget student-teacher dependency! A Metaanalysis on associations with students' school adjustment and the moderating role of student and teacher characteristics. Attachment \& human development, 1-14.

27. Skakni, I. (2018). Doctoral studies as an initiatory trial: expected and taken-for-granted practices that impede $\mathrm{PhD}$ students' progress. Teaching in Higher Education, 23(8), 927-944.

28. Jeong, H. C., \& So, W. Y. (2020). Difficulties of Online Physical Education Classes in Middle and High School and an Efficient Operation Plan to Address Them. International Journal of Environmental Research and Public Health, 17(19), 7279 .

29. Octaberlina, L. R., \& Muslimin, A. I. (2020). Efl students perspective towards online learning barriers and alternatives using moodle/google classroom during covid-19 pandemic. International Journal of Higher Education, 9(6), 1-9.

30. Tarafdar, M., Maier, C., Laumer, S., \& Weitzel, T. (2020). Explaining the link between technostress and technology addiction for social networking sites: A study of distraction as a coping behavior. Information systems journal, 30(1), 96-124.

31. Xia, M., Wang, K., Song, W., Chen, C., \& Li, Y. (2020). Non-intrusive load disaggregation based on composite deep long short-term memory network. Expert Systems with Applications, 160, 113669.

Cite This Article: Leovigildo Lito D. Mallillin et al (2021). Behavior and Attitude of Students in the New Normal Perspective of Learning. EAS J PsycholBehavSci, 3(2), 21-27. 